\title{
Femur multiapikal deformitelerinin tedavisi
}

\section{Treatment of multi-apical femoral deformities}

\author{
Mehmet Erdem¹, Levent Bayam¹, Ahmet Can Erdem² \\ 'Sakarya Üniversitesi Tıp Fakültesi, Ortopedi ve Travmatoloji Anabilim Dalı, Sakarya \\ ${ }^{2}$ Bezmi Alem Üniversitesi, Ortopedi Bölümü, İstanbul
}

\begin{abstract}
Multiapikal femur deformiteleri, genellikle metabolik hastalığın neden olduğu deformiteler olup, normal dizilimi sağlamak için multipl osteotomiler gerektirmektedir. Femoral osteotomilerin tespitinde, sirkülar veya unilateral eksternal fiksator (EF) veya eksternal fiksator yardımlı intramedullar çivileme (IM) (fixator assisted nailing -FAN) ile iM çivileme teknikleri kullanılabilir. Bu teknikler ile uygun femoral dizilim, kaynama ve kemik uzatmada birbirine yakın sonuçlar elde edilmektedir. EF ile tespitte, tedavi süresinin daha uzun olması, pin trakt (çivi yolu) enfeksiyonları, fiksator sonrası deformite rekurrensi, refraktür, yeterince konforlu olmaması dezavantajları olarak sıralanır. FAN teknikte, teknik bağımlılıkla birlikte, IM tespite bağlı, daha stabil tespit, daha az deformite rekurrensi ve refraktür, daha konforlu olması tercih edilebilirliğini artırmaktadır.
\end{abstract}

Anahtar sözcükler: femur; multiapikal deformite; eksternal fiksator; intramedullar çivi; fixator assisted nailing-FAN
Multi-apical femur deformities are generally caused by metabolical diseases and in order to achieve good alignment, multiple osteotomies are required. To stabilize femoral osteotomies, circular, unilateral external fixator (EF), fixator assisted intramedullar nailing (FAN) (fixator assisted nailing-FAN) and intramedullary (IM) nailing options can be used. Appropriate femoral alignment, healing and lengthening could be obtained using all the above techniques with similar outcome. On the other hand, there are some disadvantages when stabilising with EF such as longer treatment duration, pin-tract infections, recurrence of deformity after fixation, re-fracture and patients not feeling comfortable with it whereas in fixation with FAN techniques, despite longer learning curve, it is more preferable due to better stability, having less recurrence of deformity or re-fracture and possibly being more comfortable for the patients.

Key words: femur; multi-apical deformities; external fixator; intramedullary nailing; fixator assisted nailing-FAN
M ultiapikal femur deformiteleri, genellikle metabolik kemik hastalıklarında görülen alt ekstremite deformitelerinin bir segmenti olarak gözükmektedir.

Metabolik kemik hastalıkları, özellikle yük taşıyan alt ekstremitede, puberta öncesi fizyel büyüme bozukluğu veya mineralizasyondaki defekt nedeni ile sıklıkla iskelet deformiteleri ile kendini göstermektedir. ${ }^{[1,3,4]}$ Hipofosfatemik raşitizm, hipofosfatazya, renal osteodistrofi, Paget's hastalığı, osteogenezis imperfecta gibi kemiğin yumuşamasına (soft bone) neden olan metabolik kemik hastalıkları, alt ekstremite uzun kemiklerin multiapikal deformitelerine neden olmaktadır. ${ }^{[1-5]}$ Hastaların; ağrı, topallama, instabilite, şekil bozuklukları ve yürüme problemleri başlıca başvuru nedenlerini oluşturmaktadır.
Metabolik kemik hastalıklarında gözlenen deformiteler; ya birbirinden farklı belirgin deformiteler ya da tüm femur boyunca, uzun eğriliğin - bowing'inde oluşan multiapikal deformiteler olarak ortaya çıkmaktadır. ${ }^{[3-6]}$

Bu multiapikal femoral deformiteler, genelliklekompleks yapıya sahiptir. ${ }^{[1-3,7,8]}$ Ayrıca, bu hastalarda mevcut olan kötü kemik kalitesi, malalignmentın(dizilim bozukluğunun) optimal düzeltilmesini de önlemektedir. ${ }^{[1,3]}$

Daha sıklıkla görülen bir metabolik hastalık olan raşitizmde; alt extremitelerde, genellikle multiapikal ve kompleks deformiteler oluşmakta, medikal tedaviye rağmen rezidüel deformiteler gelişmekte ve cerrahi korreksiyon gerektirmektedir. ${ }^{[2]}$ Ayrıca metabolik hastalıklarda, multiapikal angulasyon ve kısalık özellikle

- Illetişim adresi: Prof. Dr. Mehmet Erdem, Sakarya Üniversitesi Tıp Fakültesi, Ortopedi ve Travmatoloji Anabilim Dalı, Sakarya Tel: 0535 - 8193532 e-posta: drmehmeterdem@gmail.com

- Geliș tarihi: 28 Kasım 2019 Kabul tarihi: 29 Ocak2020 
birlikte görülebilmektedir. Böylece, bu deformitelerin düzeltilmesi planlanırken, uzatmanın da birlikte yapılacak şekilde planlaması ve ona göre de cerrahi tekniğin belirlenmesi gerekmektedir.

Metabolik hastalıklarda alt ekstremite uzun kemiklerinde eğrilme - bowing oluşması; kemiğin yumuşak yapısı nedeni ile yük binen alt ekstremitelerde, multiple stress kırıkları ve remodeling nedeni ile ikiden fazla seviyede apeksi olan multiapikal deformitelerin geliştiği bildirilmektedir. ${ }^{[5]} \mathrm{Bu}$ femoral bowing deformitelerini düzeltmek için multiapikal, genellikle iki veya daha fazla osteotominin yapılması, femoral anatomik ekseni düzeltmek için gerekmektedir (Şekil 1).

Multiapikal femoral deformitelerin cerrahi korreksiyonunda; sadece eksternal fixator (EF) teknik (ilizarov sirkuler eksternal fiksator - SEF, unilateral raylı eksternal fiksator - LRS veya hybrid eksternal fiksator), kombine teknik - fiksator yardımlı kilitli intramedullar (IM) çivileme (fixator assisted nailing - FAN) ve sadece iM çivileme cerrahi teknikleri kullanılabilir. EF veya FAN teknikleri ile, deformite korreksiyonu beraberinde eş zamanlı kısalık probleminde, kemik uzatma cerrahisi de yapılabilmektedir.

\section{CERRAHI TEKNIK}

\section{Illizarov EF ile Femur Deformite Düzeltme Tekniği}

ilizarov EF çerçeve (frame)'si, deformite ile uyumlu, deformite konfugurasyonda hazırlanarak, osteotomi sayısına göre menteşe sistemi kurularak uygulanır. Proksimal ve distal halkalar, kemiğe her iki planda dik yerleştirilir. Distal halka, kemiğe dik olarak gönderilen referans Kirshner (K) teli ile tespit edilir, daha sonra proksimaldeki halka, kemiğe dik gönderilen Schanz çivisi ile tespit edilir. Sonrasında, tüm halkalar, nörovasküler yaralanmadan kaçınmak için, çoğunlukla schanz çivileri ve $\mathrm{K}$ telleri ile sistem stabil hale getirilir. "Drill hole" tekniği ile osteotomi yapılır ve tedrici olarak deformiteler düzeltilir. Femoral kısalık mevcut ise eş zamanlı tedrici distraksiyona, 7-10 gün bekleme periyodu sonrasında $4 \times 0,25$ milimetre $(\mathrm{mm}) /$ gün olarak başlanır (Şekil 2).[2,9-11]

\section{LRS EF ile Femur Deformite Düzeltme Tekniği}

Schanz çivileri, deformite segmentlerin proksimal ve distalinde femur anatomik eksenine dik olarak, önce en distal ve en proksimalde gönderilir. LRS gövdesi bağlanır ve diğer schanz çivileri aynı teknik ile gönderilir. Perkutan "drill hole" tekniği ile osteotomi yapıldıktan sonra deformite segmentleri akut korreksiyonu yapılır. Femoral uzatma gereksiniminde ise eş zamanlı tedrici distraksiyona, 7-10 gün sonrasında $4 \times 0,25 \mathrm{~mm} /$ gün olarak başlanır (Şekil 3).

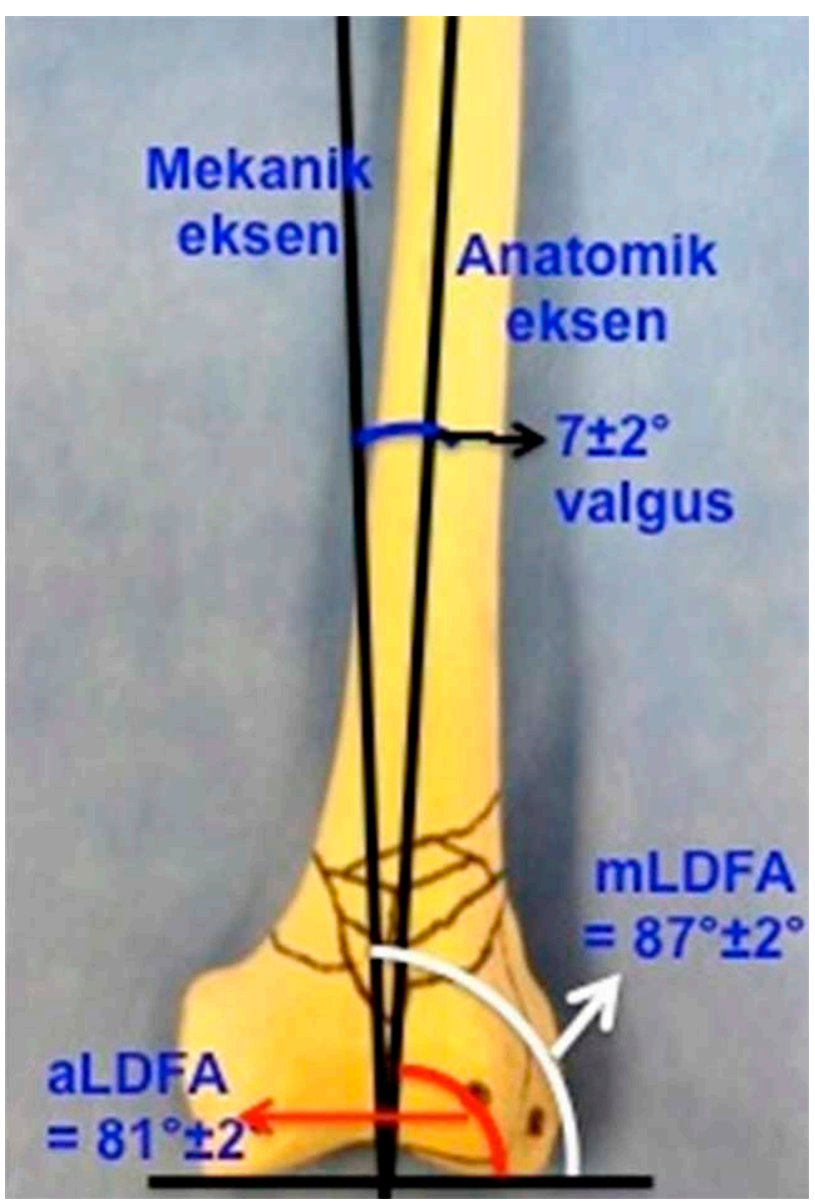

Şekil 1. Mekanik ve anatomik eksenler.

\section{FAN ile Deformite Düzeltme Tekniği}

Paley ve ark. tanımladığı gibi[i2,4] LRS EF lateralden uygulanmakta, EF pinleri, iM çivi ile çakışmamak ve engellememek şartı ile, femurun hem proximal hem de distalinde posteriordan yerleştirilmektedir. Pinlerin yönleri, karşılık gelen fragmanlara, hem frontal hem de sagittal planda diktir. Osteotomi multiple hole (delik) tekniği ile yapilır. ${ }^{[2,5,6]}$ CORA (center of rotation of angulation)'nın distal femur eklem seviyesine yakın deformitelerinde, osteotomi daha proksimalden yapılır ve ameliyat öncesi hesaplanan miktarda korreksiyon ile birlikte, osteotomi bölgesinde manipülasyon ile translasyon ilave edilir. Düzeltme, her üç planda (frontal, sagittal ve rotasyonel) akut olarak yapilır. Intraoperatif radyografik veya floroskopi ile malalignment testi yapılarak, düzeltme kontrol edilir. ${ }^{[2,5,6]}$ Yeterli korreksiyon teyit edildikten sonra, perkutan iM retrograd çivi distal femurdan gönderilir. IM çivi kilitleme sonrasında, metafizer bölge ve geniş medullar kanallarda kanalı daraltan birbirine dik 

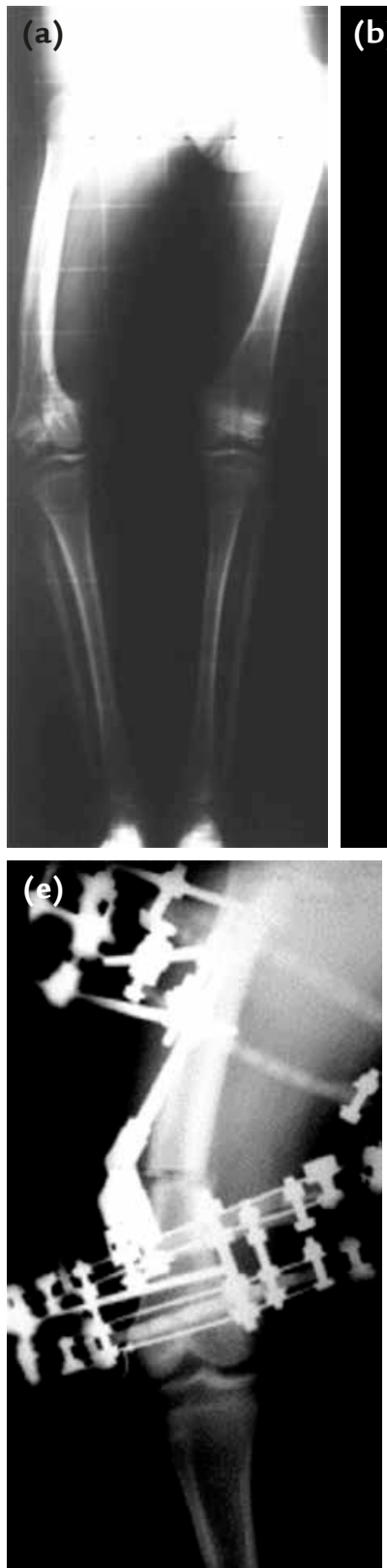
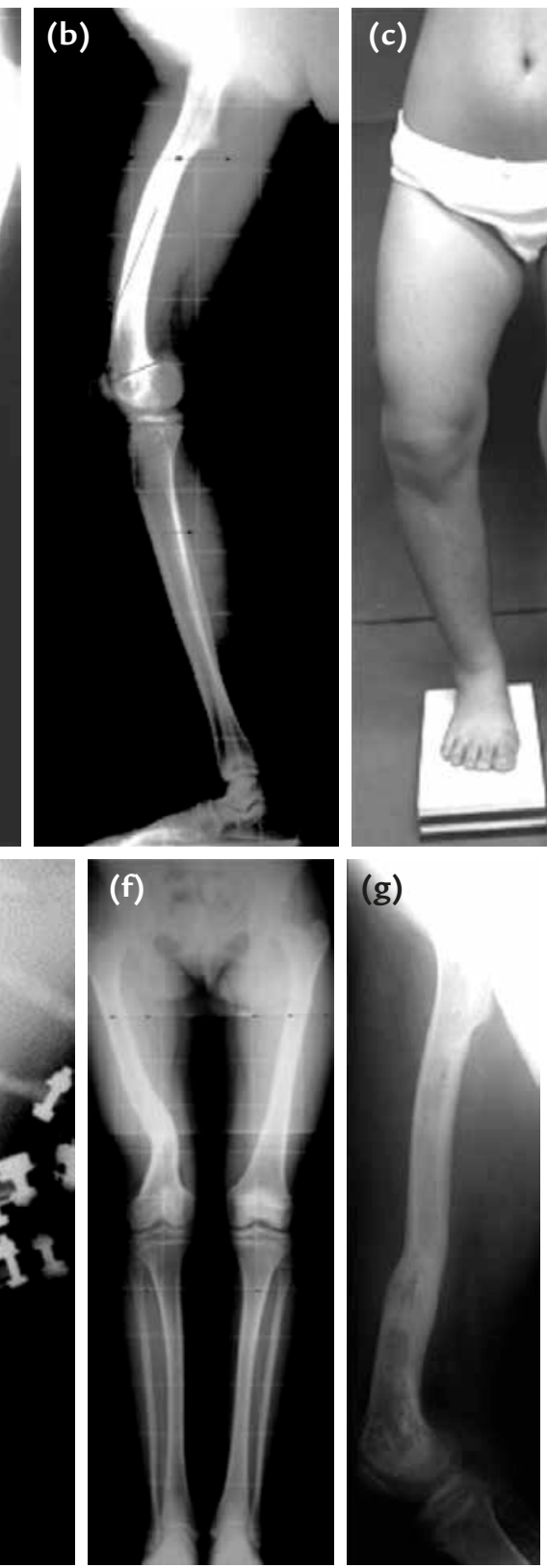
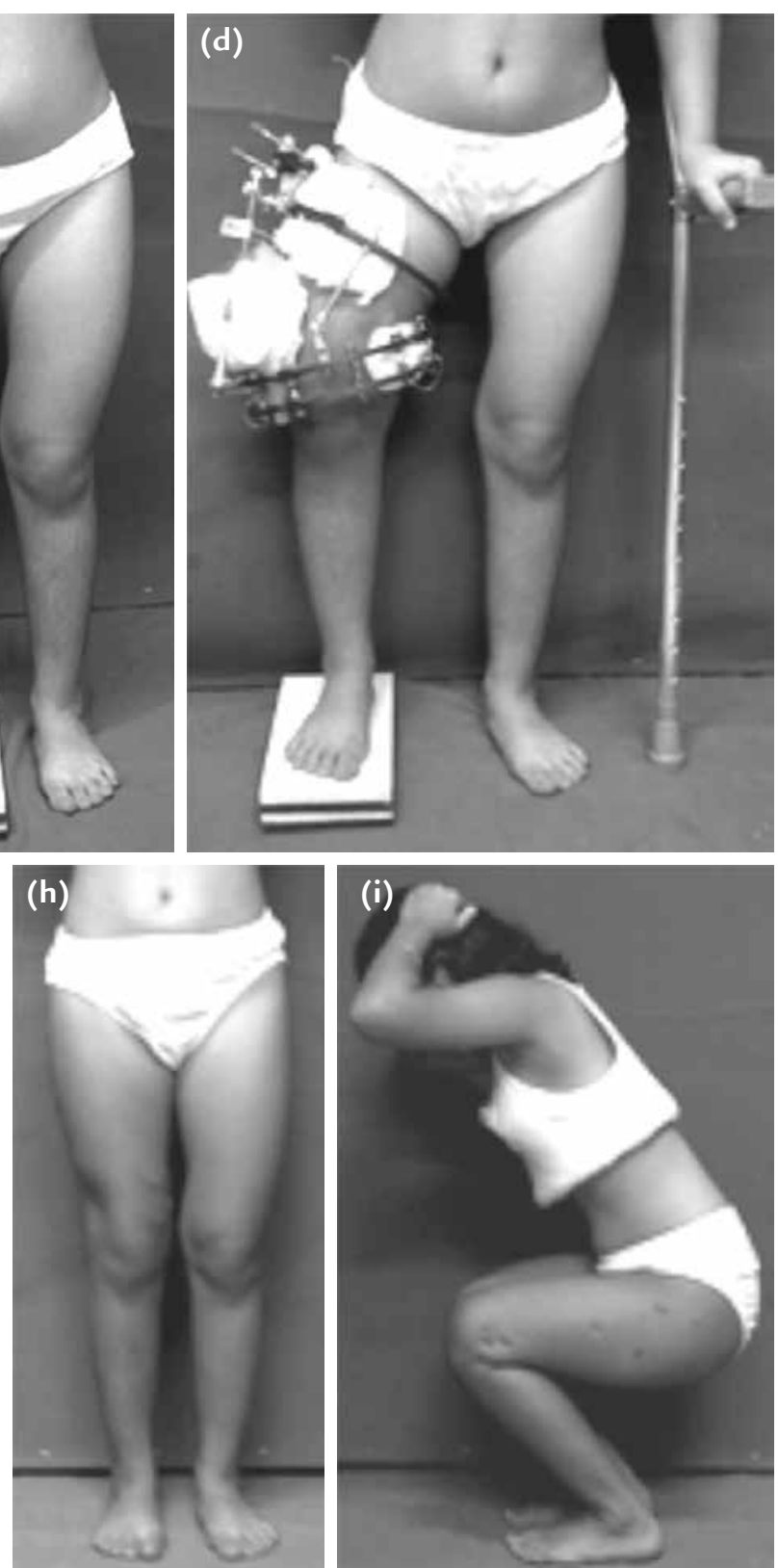

Şekil 2. a-i. On üç yaş, bayan. Femoral deformite kaynaklı varus ve prokurvatum deformitesi ve $5.5 \mathrm{~cm}$ kısalık (a-c). ilizarov $E F$ ile her iki planda femur deformite korreksiyonu ve $5 \mathrm{~cm}$ uzatma $(\mathrm{d}-\mathrm{i})$.

açıda farklı planlarda polar blok vidaları ile stabilite arttırılır ${ }^{[2,5,6,9,12]}$ ve sonrasında LRS EF çıkartılır (Şekil 4).

\section{TARTIŞMA}

Multiapikal deformiteler, genellikle bütün uzun kemiklerin bowing'inden (eğiminden) kaynaklanır. Bunu düzeltmek için, sekonder iyatrojenik deformiteden kaçınmak ve kemiği düz hale getirebilmek için, birden fazla osteotomi gerektirirr. ${ }^{[2,4,6]}$ illeri derecede bowing (eğrilik)'lerde daha fazla deformite apeksi ve deformite merkezi CORA bulunmakta olup, kısa segmentleri içerecek şekilde daha fazla sayıda osteotomiyi gerektirmektedir. ${ }^{[5]}$

Multiapikal femur deformitelerinin hafif vakaların$\mathrm{da}$, sadece bir osteotomi ile mekanik eksen üzerinden düzeltilebilir, fakat anatomik eksen düzeltilmemiş olur. [5] Fakat femurda etrafı yoğun kas kitlesi ile kaplı olması nedeni ile femurdaki anatomik eksen deformitesi kozmetik bir sorun oluşturmamaktadır (Şekil 2). 

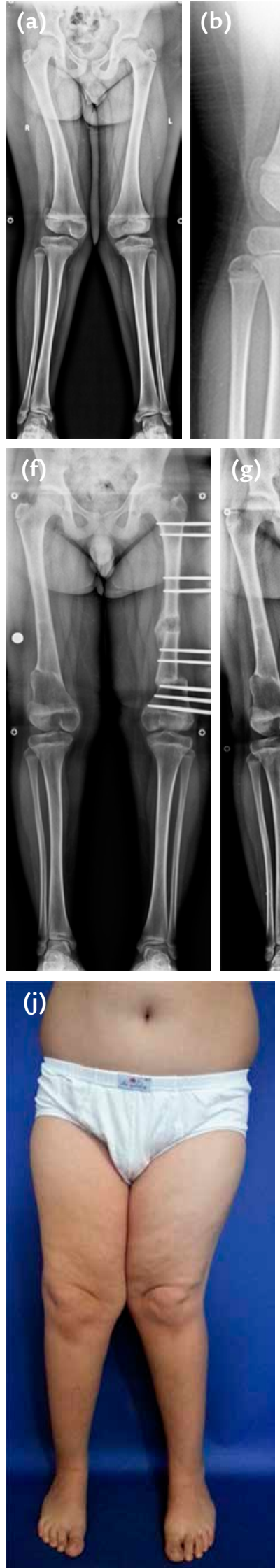

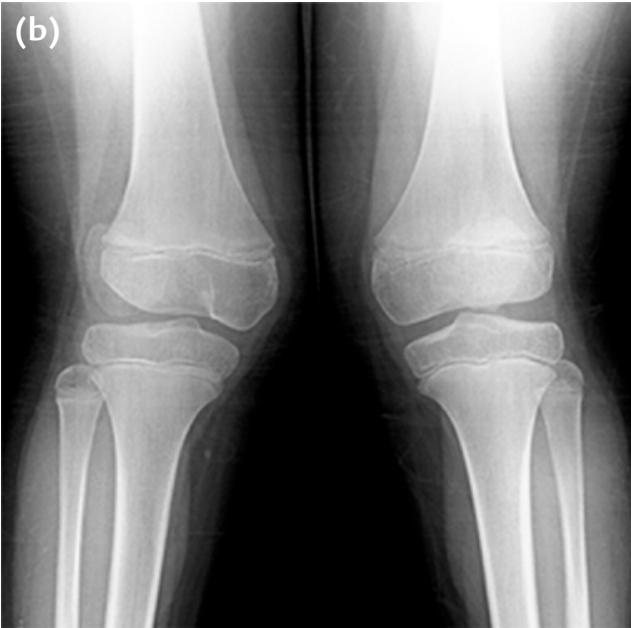

(h)
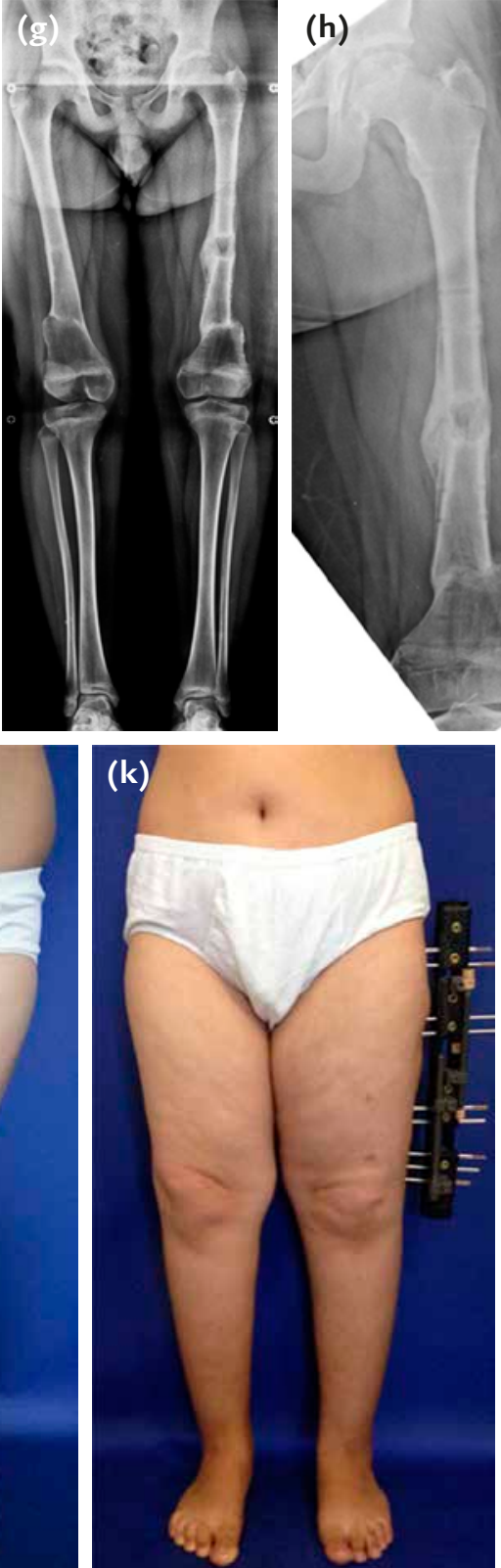
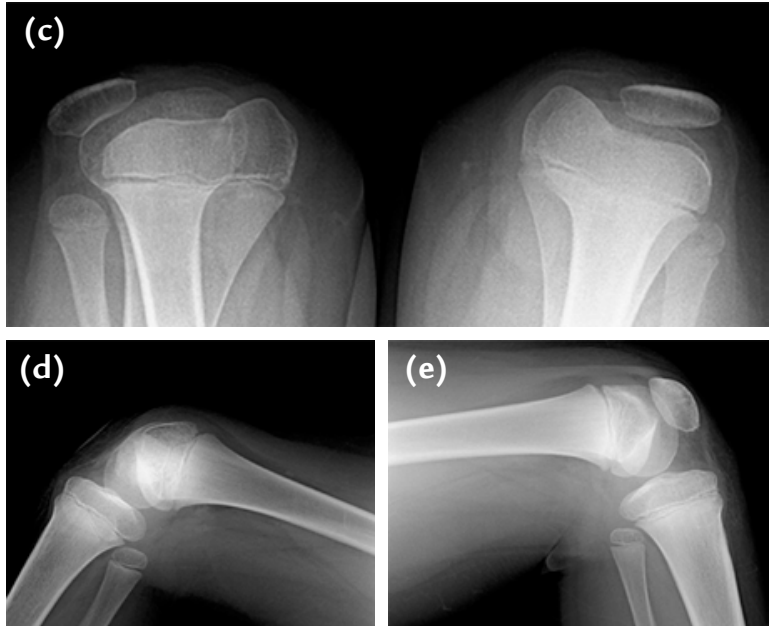

Şekil 3. a-I. On dört yaş, erkek. Bilateral genu valgum deformitesine neden olan femoral deformite, bilaterel patellofemoral instabilite (a-e). Unilateral LRS EF ile bilateral femur deformite korreksiyonu ve eş zamanlı uzatma (sol femur, iki seviyeli osteotomi ve $3 \mathrm{~cm}$ uzatma) $(f-I)$. 

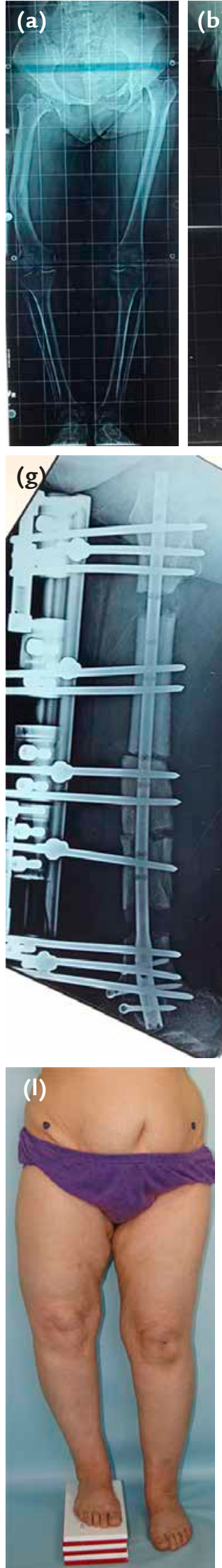
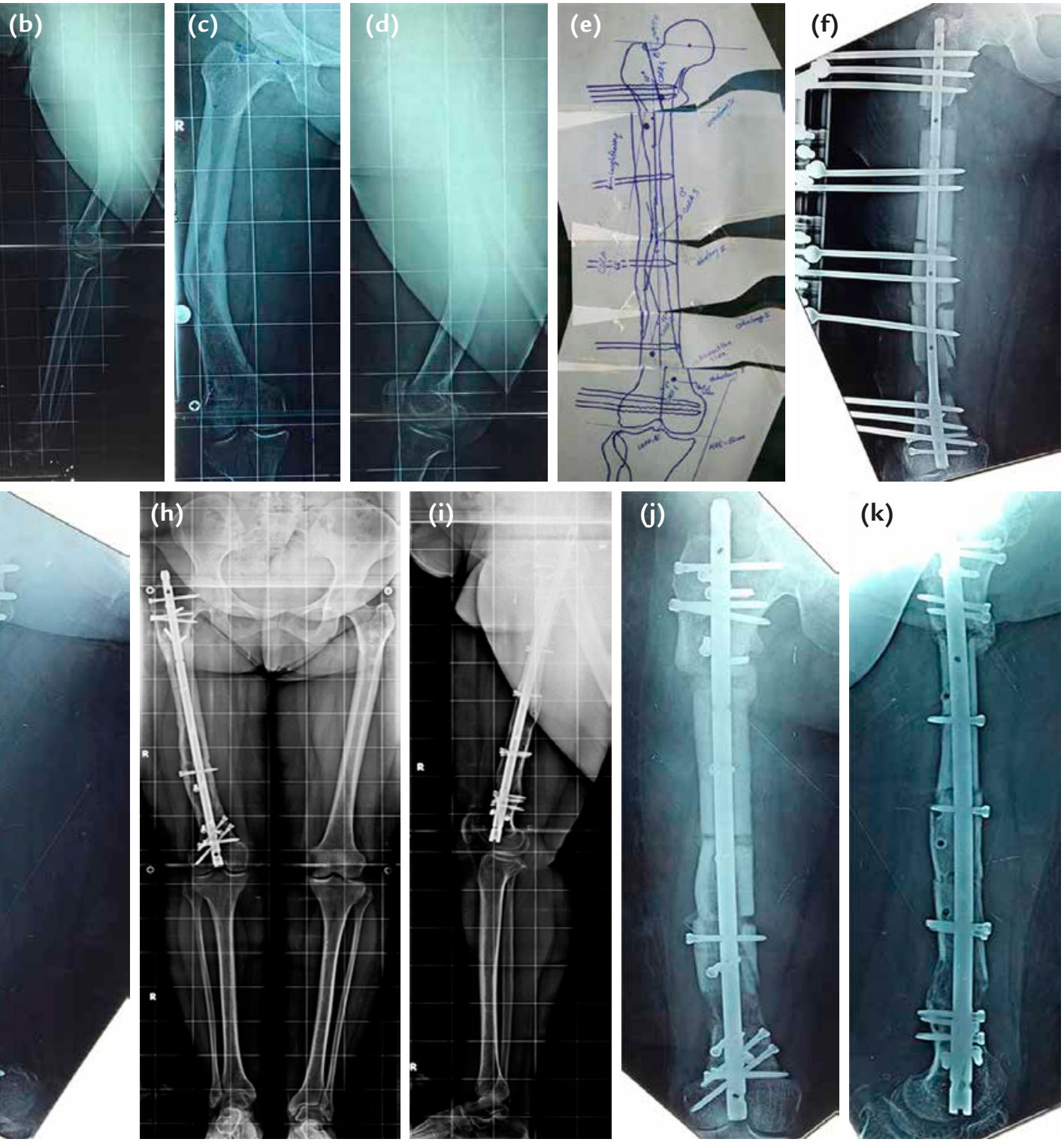

(m)

(n)

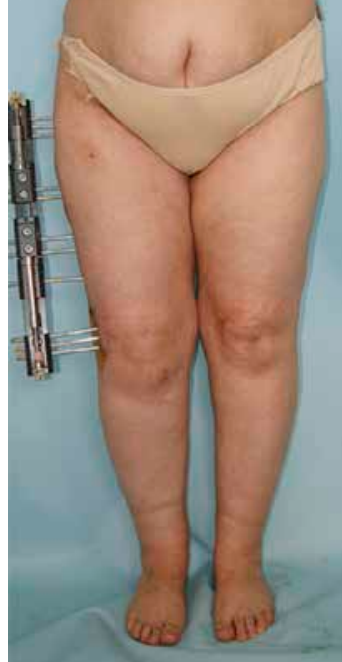

Şekil 4. a-n. Kırk yaş, bayan. Femoral her iki planda multiapikal deformite ve kısalık (a-d). Deformite planlaması sonrası dört seviyeli osteotomi ve LRS EF ile korreksiyon ve İM çivi üzerinden uzatma $(4 \mathrm{~cm})$ ve uzatma tamamlanması sonrasında daha kalın IM çivi değişimi (e-k). 
Multiapikal deformitelerde osteotomileri, teknik olarak, deformitenin apeks'inden - CORA'dan yapmak gerekir. Ekleme çok yakın olan distal femoral yerleşimli multiapikal deformitelerde, osteotomi biraz daha proksimalden yapılıp, anatomik eksen deformitesi oluşturmamak için translasyon ile birlikte korreksiyon yapmak gerekir. ${ }^{[5]}$

Metabolik kemik hastalığından dolayı deformiteler, multiple ekstremite segmentinde oluşur ve femur da bu segmentlerden birini oluşturur. Eğer hastalık, metabolik olarak kontrol altında değil ise, korrektif (düzeltici) osteotomi sonrasında deformiteler tekrar etme eğilimindedir. ${ }^{[2,7]}$ Ayrıca, metabolik kemik hastalığında deformitelerin operatif korreksiyonu sonrasında, kemiğin iyileşme süresi de artma eğiliminde olup, nonunion ve rekürrens için artmış potansiyele sahiptir. ${ }^{[1,4,6]}$ Altta yatan hastalığın medikal kontrolü ile birlikte kalsiyum imbalansını önlemek için bu hastaların erken mobilizasyonu gereklidir ve bunun için stabil fiksasyon önerilmektedir. ${ }^{[2,13]}$ Bu nedenle de, deformite korreksiyonun da IM çivileme yönteminin tercih edilmesi, intramedüller stabil tespit ile deformitenin rekürrensini, kaynamama olasılığını azaltmakta ve erken mobilizasyona da imkan sağlamaktadır.

Rubinovitch ve ark. hipofosfatemik raşitizm olan hasta serisini içeren çalışmasında, 44 alt ekstremite osteomisi, kısaltma ve kompresyon plak ile tespit yapmışlar; ortalama 51 ay takip etmişlerdir. Ekstremite segmentlerinin \%27'sinde deformitenin nüksü görülmüştür. Metabolik hastalık, erken periodik dönemde kontrol altında olsa da, hastaların 1/3 ünde, metabolik dekompansasyon gelişmiş̧ir. ${ }^{[8]}$ Oysaki düzeltme sonrası IM çivi ile osteosentez yapıldığında, postoperatif periyodda metabolik dekompansasyon gelişse bile; IM çivi deformite rekürrensine karşı stabil bir koruma sağlamaktadır. ${ }^{[2,14,15]}$

illizarov EF ile osteotomi ve stabilizasyon, kontrol edilebilir deformite korreksiyonu sağlamaktadır. Ayrıca düşük enerjili osteotomi ve osteosentez için minimal intraosseoz implant kullanımından dolayı yüksek kaynama ve düşük infeksiyon oranına sahiptir. İlizarov tekniğinin diğer bir avantajı, postoperatif değişiklikler ve deformite ile eş zamanlı ekstremite eşitsizliğinde, distraksiyon yapılmasına imkan vermektedir. Fakat, pin trakt (çivi yolu) infeksiyon, ilizarov EF'un büyük hacım kitlesinin olması, konforun azalması, uzamış tedavi süresi dezavantajıdır. ${ }^{[2,4,6-8]}$

Raşitizm'e bağlı multiapikal deformite korreksiyonunda, FAN tekniği ile ilizarov EF tekniğinin karşılaştırıldığı çalışmada ${ }^{[2]}$, ilizarov EF grubunda, $66 \%$ oranında pin trakt (çivi yolu) enfeksiyonu tespit etmişlerdir. Fakat bunlar yüzeyel enfeksiyonlar olup lokal yara bakımı ve antibiyoterapi ile tedavi edilmiştir.
Multiapikal deformitelerde, metabolik hastalıklarda her iki femur segmentine ilaveten diğer ekstremite segmentlerinin tutulumu da yüksektir. Bir veya ardışık operasyonlarda, sadece ilizarov EF veya LRS EF ile tüm deformitelerin korreksiyonu, hastanın konforunu oldukça olumsuz etkilemekte ayrıca hasta uyumunu da azaltmaktadır.

Song ve ark. ${ }^{[16]}$, multiapikal deformite korreksiyonunda, IM çivinin sınırlı stabilite sağlayabildiğini ve eğer tek başına kullanılırsa, yüksek komplikasyon riski ile ilişkilendirmişlerdir. Onların çalışmaları, IM çivi tespit, progresif diyafizyel deformitenin önlenmesine yardım edebilir; fakat metafizyel bölgede fiksasyon yetersiz olduğundan dolayı, kalan büyüme periyodunda metafizde gelişen deformiteyi kontrol edemez. Onların düşüncesi, eksternal fiksatör yardımlı tedrici düzeltme ve sonrasında IM çivi ile tespitin, daha iyi sonuçlar verdiği ve EF'un başta eklem sertliği ve pin bölge enfeksiyonu olmak üzere komplikasyonları azalttığı yönündedir.

Stanitsky ${ }^{[1]}$ ilizarov frame (çerçeve) ile tedavi edilen hastalarda, metabolik kemik hastalığı için, eksternal fiksator indeksi (EFI), femoral uzatma için olanlarda, normalden iki kat daha miktarda bulmuştur. Osteotomi bölgesinde kaynama problemi saptanmamış; düşük evrede pin bölge enfeksiyonu ve önemsiz mekanik eksen translasyonu görülmüş, nihai sonuç üzerine hiçbir etkisi bulunmamıştır.

Unilateral EF ile multiapikal femoral deformitelerin akut düzeltilmesi ve IM çivi ile tespitin birleştirildiği FAN tekniğinin avantajları; akut dizilimin restorasyonu, normal yaşama erken dönme ve yüksek hasta konforu sağlamasıdır. Deformite ile birlikte ekstremite eşitsizliğinin bulunduğu vakalarda, unilateral LRS EF ile IM çivi üzerinden tedrici distraksiyonun yapılarak bacak eşitliği sağlanır ve uzatma bitiminde iM çivi kilitlenip EF çıkartılır. ${ }^{[2]}$

FAN tekniği ile femoral multiapikal deformitelerin düzeltilmesinde; minimal invazif olması, hasta uyumu ve internal tespit konforu en önemli üstünlükler olarak göze çarpmaktadır. Ayrıca, medüllar kanalda bırakılan IM çivi, metabolik dekompanse hale gelen hastalarda bile uzun dönemde, deformitenin nüks etmesini önleyebilmektedir.

FAN tekniğinde, birden fazla osteotomi seviyesi düşünüldügüüde, segment fiksasyonu için ekstra (fazladan) delik, preoperatif olarak IM çivi üzerinde önceden planlama ile açılmaktadır. Planlanan birbirine farklı planlarda dik ekstra (fazladan) delik, küçük kemik fragmanlarının stabilitesini artırmakta, hem frontal hem de sagittal planda stabiliteyi artırmaktadır. ${ }^{[2]}$ ileri derece deformitelerde, FAN tekniği, yetersiz düzeltme sağlayabilmektedir. 
FAN tekniğinde karşılaşılan problemler; nörovaskülar yaralanma, kompartman sendromu, kaynama gecikmesi, nonunion, deformite nüksü, ameliyat sonrası infeksiyon gelişmesine yanısıra; düzeltme kaybı, büyük açısal deformitede yetersiz düzeltme, ayrıca eş zamanlı uzatmanın gerektirdiği deformite düzeltmelerde bu tekniğin kullanımının sınırlı olduğu ifade edilmektedir. ${ }^{[4]}$

Gugenheim ve Brinker ${ }^{[14]}$ zamanı kısaltmış olsa da, FAN tekniğinin limitasyonu (sınırlaması) olarak; düzeltmeyi sınırlayan ekleme yakın angular (açısal) ve rotasyonel deformitenin büyük olması durumunu vurgulamışlardır. Ancak, unilateral EF ve angular translasyonel osteotomi ile bu durumun üstesinden gelinebilir ve IM çivi ile tespit yapılır. Fizisi açık olan vakalarda, retrograd iM çivi kullanımı FAN tekniğininin uygulanmasını sınırlamaktadır.

Eralp ve ark, raşitizm hastalığında angular deformitelerde kemik diziliminin sağlanmasında FAN tekniği ile sirkular EF tekniğini karşılaştırmışlar, her iki grupta da düzeltme oranlarında hiçbir farklılık saptamamışlardır. Her iki teknik arasında EFI kıyaslandığında, ilizarov grubundaki hastalar, daha uzun iyileşme zamanına sahip iken, FAN grubundaki hastalarda bu süre daha kısa bulunmuştur. ${ }^{[2]}$

Kocaoğlu ve ark. metabolik kemik hastalığı sonucu oluşan ve femur segmentini de içeren multiapikal deformiteli 17 hastanın 27 femur ve 16 tibiasına FAN tekniğiyle osteotomi ve iM tespit yapmışlardır. 3 hastanın 6 femurunda kısalık nedeni ile eş zamanlı ortalama 7,2 $\mathrm{cm}$ uzatma ilave etmişlerdir. IM çivilemenin kullanımının, deformitenin rekurrens ve tekrar kırık oluşmasını engellediğini, ileri derecede alt ekstremite deformitesi olan hastalarda, bu tekniğin etkin ve güvenli olduğunu bildirmişlerdir. ${ }^{[17]}$

\section{SONUÇ}

Multiapikal femur deformiteleri, genelikle metabolik hastalıkların neden olduğu deformiteler olup, normal dizilimi sağlamak için multiple (çoklu) osteotomiler gerekmektedir. Femoral osteotomi tespitinde, teknik olarak sirküler EF, unilateral EF veya FAN ile IM çivileme yapılabilir. Bu teknikler ile uygun femoral dizilim, kaynama ve kemik uzatmada birbirine yakın sonuçlar elde edilmektedir. EF ile tespitte, tedavi süresinin daha uzun olması, pin trakt (çivi yolu) enfeksiyonları, fiksator sonrası deformite rekürrensi, refraktür, yeterince konforlu olmaması dezavantajları olarak görülmektedir. FAN tekniğinin; teknik bağımlılıkla birlikte, iM tespite bağlı daha stabil tespit sağlaması, daha az deformite rekürrensi ve refraktür görülmesi daha konforlu olması tercih edilebilirliğini artırmaktadır.

\section{KAYNAKLAR}

1. Stanitski DF. Treatment of deformity secondary to metabolic bone disease with Ilizarov technique. Clin Orthop Relat Res 1994;(301):38-41. Crossref

2. Eralp L, Kocaoglu M, Toker B, Balcı HI, Awad A. Comparison of fixator-assisted nailing versus circular external fixator for bone realignment of lower extremity angular deformities in rickets disease. Arch Orthop Trauma Surg 2011;131(5):5819. Crossref

3. Mankin HJ. Rickets, osteomalacia and renal osteodystrophy: an update. Orthop Clin North Am 1990 21(1):81-96.

4. Paley D, Herzenberg JE, Bor N. Fixator assisted nailing of femoral and tibial deformities. Tech Orthop 1997;12(4):26075. Crossref

5. Paley D, Tetsworth K. Mechanical axis deviation of the lower limbs. Preoperative planning of multiapical frontal plane angular and bowing deformities of the femur and tibia. Clin Orthop Relat Res 1992;(280):65-71. Crossref

6. Paley D, Herzenberg JE, Tetsworth K, McKie J, Bhave A. Deformity planning for frontal and sagittal plane corrective osteotomies. Orthop Clin North Am 1994;25(3):425-65.

7. Kanel JS, Price CT. Unilateral external Wxation for corrective osteotomies in patients with hypophosphatemic rickets. J Pediatr Orthop 1995;15(2):232-5. Crossref

8. Rubinovitch M, Said SE, Glorieux FH, Cruess RL, Rogala E. Principles and results of corrective lower limb osteotomies for patients with vitamin D-resistant hypophosphatemic rickets. Clin Orthop Relat Res 1988;(237):264-70. Crossref

9. Paley D. Length Considerations: Gradual Versus Acute Correction of Deformities. In: Principles of Deformity Correction, Chap. 10. Berlin Heidelberg: Springer-Verlag; 2002. pp.269-89. Crossref

10. Paley D, Tetsworth K. Percutaneous osteotomies. Osteotome and Gigli saw techniques. Orthop Clin North Am 1991;22(4):613-24.

11. Paktiss AS, Gross RH. Afghan percutaneous osteotomy. J Pediatr Orthop 1993;13(4):531-3. Crossref

12. Paley D, Catagni MA, Argnani F, Villa A, Bijnedetti GB, Cattaneo R. Ilizarov treatment of tibial nonunion with bone loss. Clin Orthop Relat Res 1989;(241):146-65. Crossref

13. Price $C T$. Unilateral fixators and mechanical axis alignment. Orthop Clin North Am 1994;25(3):499-508.

14. Gugenheim JJ Jr, Brinker MR. Bone realignment with use of temporary external fixation for distal femoral valgus and varus deformities. J Bone Joint Surg Am 2003;85(7):1229-37. Crossref

15. Eralp L, Kocaoglu M, Cakmak M, Ozden VE. A correction of windswept deformity by fixator assisted nailing. A report of two cases. J Bone Joint Surg Br 2004;86-B(7):1065-8. Crossref

16. Song HR, Raju SWJ, Kumar S, Lee SH, Suh SW, Kim JR, Hong JS. Deformity correction by external Wxation and/or intramedullary nailing in hypophosphatemic rickets. Acta Orthop 2006;77(2):307-14. Crossref

17. Kocaoglu M, Bilen FE, Sen C, Eralp L, Balci HI. Combined technique for the correction of lower-limb deformities resulting from metabolic bone disease. J Bone Joint Surg $\mathrm{Br}$ 2011;93-B(1):52-6. Crossref 